\title{
REQUISITOS PARA INTERAÇÃO EM AMBIENTE DIGITAL BILÍNGUE
}

\author{
REQUIREMENTS FOR INTERACTION IN BILINGUAL DIGITAL \\ ENVIRONMENT
}

\author{
Elisa Maria Pivetta, Daniela Satomi Saito, \\ Vania Ribas Ulbricht e Ana Margarida Pisco Almeida
}

\begin{abstract}
Este artigo descreve a otimização do ambiente Moodle fundamentado na teoria das comunidades de prática, com desenvolvimento e integração de tecnologias para atender um público bilíngue (português/libras), gerando o MooBi - Moodle Bilíngue. Os testes de verificação dos requisitos de acessibilidade possibilitaram detectar não conformidades e a gerar especificações e sugestões para um ambiente digital bilíngue de ensino e aprendizagem.

Palabras clave: Acessibilidade Digital em AVEA, Libras, Bilíngue, Comunidades de Prática.

This article describes the optimization of the Moodle environment based on the theory of communities of practice, with the development and integration of technologies to serve a bilingual public (portuguese / libras), generating MooBi - Bilingual Moodle. Tests to verify accessibility requirements have made it possible to detect nonconformities and to generate specifications and suggestions for a bilingual virtual learning environment.
\end{abstract}

Keywords: Accessibility, VLE, Sign Language, Bilingual, Communities of Practice. 


\section{Introdução}

O ser humano possui um altruísmo biológico que fundamenta o ato de interagir, cooperar, compartilhar e viver em sociedade que se concretiza na linguagem. Ter uma língua diz respeito à autonomia pessoal e possibilita ao indivíduo gerir livremente a sua vida [Maturana \& Varella, 1995]. Na educação, a autonomia revela-se como sendo a capacidade do aluno de aprender sem dependência exclusiva, administrando seu tempo no aprendizado e escolhendo de forma eficiente as fontes de informação disponíveis.

No Brasil existem duas línguas oficiais, Português e Libras. A Libras é a Língua Brasileira de Sinais, que foi instituída pela Lei 10.436/2002. Pressupõe-se que a Libras, por ser oficialmente uma língua nova, ainda não logrou os resultados pretendidos. De vez que são poucas as instituições de ensino estruturadas e capazes de conduzir uma aprendizagem com base no suporte bilíngue (Português e Libras).

A inclusão tem como objetivo desenvolver o potencial de cada indivíduo, independente de sua língua, eliminando a discriminação e promovendo a coesão social. A educação inclusiva é um processo, que pode ser entendido como uma estratégia, para levar educação a todos, atendendo às necessidades de aprendizagem. Neste contexto, os ambientes digitais são facilitadores da interação dos indivíduos e do compartilhamento das informações. Todavia para que as informações se transformem em capital do conhecimento é crucial que o sistema apresente características de interatividade e compartilhamento. No que tange a acessibilidade digital, requer prioritariamente que o ambiente seja bilíngue.

Bauman e Murray (2012) entendem que, ao incluir a língua de sinais na biodiversidade cultural, ampliam-se as concepções do potencial humano para a linguagem, para a expressão, para a criatividade, favorecendo a interação e a formação de comunidades, proporcionando autonomia. Os autores denominaram de "ganho surdo" a diversidade sensorial e cognitiva dos surdos, a qual tem o potencial de contribuir para o bem de todos. Com isso, por meio de investigações exploratórias de conhecimento, este trabalho procurou visualizar as diferenças e habilidades dos surdos, na busca deste "ganho surdo", para propor requisitos para um ambiente virtual bilíngue acessível que favoreça a interação entre português e libras.

1 Software livre, que se pode redistribuir e/ou modificar sob os termos da GNU General Public License, conforme publicado pela Free Software Foundation.

Questões de acessibilidade em ambientes virtuais de ensino e aprendizagem (AVEA) aparentam não ser problemáticas. No entanto existem barreiras de interface e linguísticas que podem impedir a interação e a aquisição do conhecimento. A lei $n^{0} 13.146$, de 6 de julho de 2015, conceitua barreira como qualquer entrave ou obstáculo que limite ou impeça a participação social da pessoa e o exercício de seus direitos à acessibilidade, à liberdade de expressão, informação e comunicação (BRASIL, 2015).

O Moodle (Modular Object-Oriented Dynamic Learning Environment) é um AVEA de código fonte aberto (open source) ${ }^{\mathbf{1}}$, com cerca de 76 mil sites registrados no mundo, e uma base de aproximadamente 88 milhões de usuários (MOODLE, 2015). Todavia, mesmo sendo um dos ambientes virtuais mais utilizados na educação, possui barreiras e rupturas na questão de acessibilidade. Estudos como, por exemplo, de Gabardo et al., (2010); Fajardo et al. (2009); Saito e Ulbricht, (2012); Schneider (2012); e Trindade (2013), revelaram que o ambiente Moodle precisa ser aprimorado para atender às necessidades dos surdos. Nesse cenário, esse artigo apresenta requisitos para uma plataforma digital de ensino e aprendizagem bilíngue (Português e Libras), balizado pelo arcabouço teórico das Comunidades de Prática [Lave \& Wenger, 1991]. No entendimento de que o conhecimento não se limita a exposição de conteúdos, leituras e provas, mas depende das relações, do diálogo, do engajamento, do compromisso, da participação, das interações entre os participantes das comunidades, sejam elas formais ou informais [Hutchins 2000; Rézeau, 2001; Lave; Wenger, 1991; Primo, 2003, Wenger et al., 2005].

\section{Metodologia}

- A metodologia empregada para desenvolver este estudo está divido em quatro fases.

- Fase exploratória de conhecimento:
- Revisão Sistemática da Literatura - Para iniciar a pesquisa e verificar o estado do conhecimento, foi realizada uma revisão sistemática da literatura, utilizando a metodologia Cochrane (2012). 
- Pesquisa qualitativa: Aplicada as técnicas: entrevistas e ensaios de interação (Brasil e Portugal) e questionário eletrônico.

a. Elicitação de requisitos e desenvolvimento do protótipo funcional - levantamento dos requisitos (funcionais e não funcionais), para interação em comunidades de prática em ambiente virtual bilíngue. Com base nessas informações foi desenvolvido o protótipo com a finalidade de verificar junto ao público alvo se os requisitos elicitados são condizentes com um ambiente bilíngue para interação em comunidades de prática. A otimização do ambiente buscou atender os requisitos levantados tanto pela literatura quanto pelas pesquisas realizadas e descritas em Pivetta et al., (2013).

b. Verificação dos requisitos no MooBi - a verificação dos requisitos no protótipo foi realizada por meio da técnica ensaios de interação e como complemento um questionário, diretamente com o público alvo (professores e alunos, surdos e ouvintes).

c. Especificação dos requisitos - em resposta a verificação é descrita a especificação.
1 Formadores são professores surdos portugueses que trabalham na formação do aluno surdo.

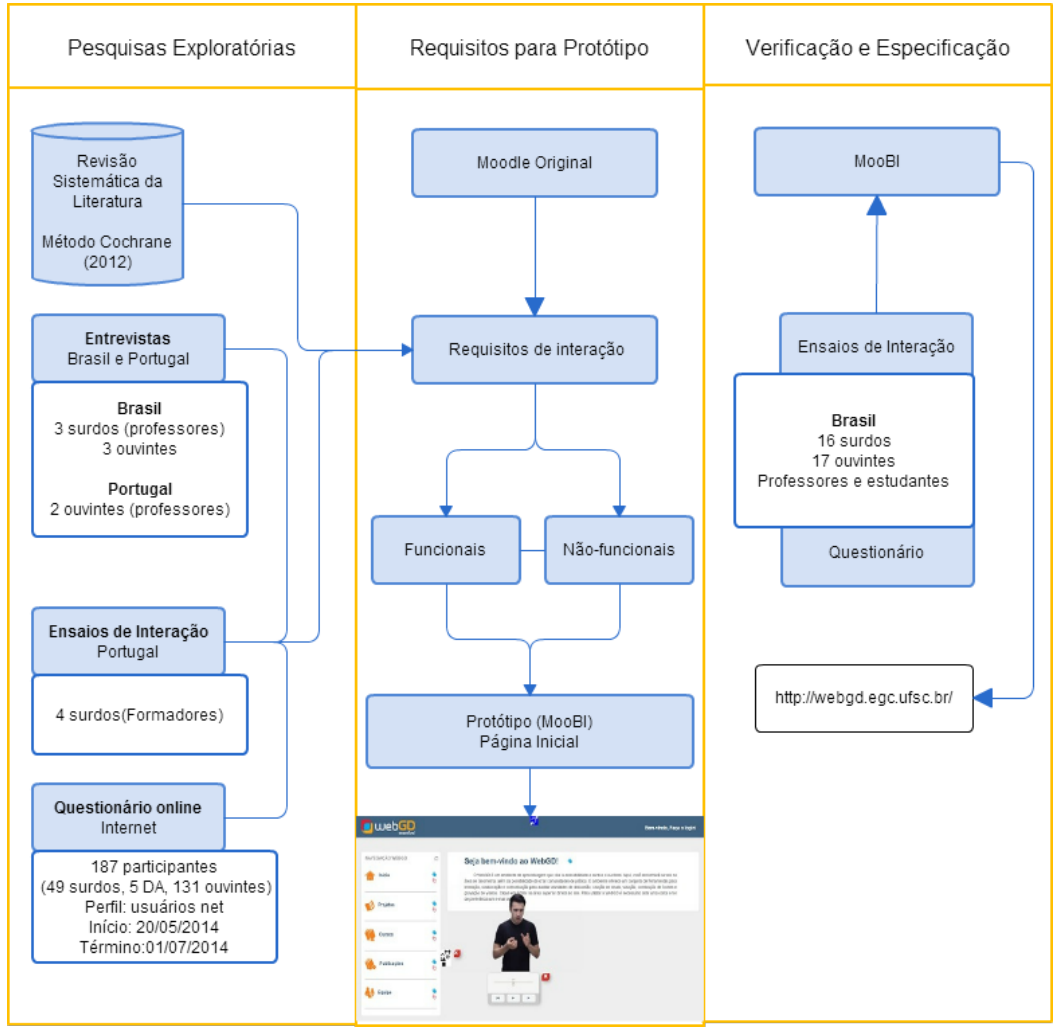

Fig. 1 - Procedimentos metodológicos
A pesquisa exploratória concretizou-se por meio de entrevistas semiestruturadas, com oito participantes brasileiros, conhecedores da plataforma Moodle (objeto de estudo), dos quais, seis brasileiros (três surdos e três ouvintes) e dois portugueses (ouvintes/intérpretes). Em Portugal foi realizado um ensaio de interação no Moodle com quatro formadores $^{2}$ surdos. A modalidade ensaio foi escolhi- da porque os quatro participantes não tinham conhecimento prévio da plataforma. Para fechar esta etapa, a qual buscava saber as barreiras e rupturas do ambiente Moodle foi propagado na internet um questionário eletrônico. No total, 187 pessoas responderam o questionário. Desse número, 131 eram ouvintes, 49 eram surdos e cinco deficientes auditivos (DA). 
2 Projeto gráfico que prevê a adaptação do layout ao dispositivo (smartphone, tablets, desktops e notebooks - sejam elas pequenas ou grandes resoluções). epequenas ou grandes resoluções).
A partir do conhecimento adquirido, a segunda etapa consistiu em elicitar os requisitos e delinear um protótipo de ambiente bilíngue acessível que atenda a teoria de Comunidades de Prática. Em resposta otimizou-se a plataforma Moodle, criando um ambiente denominado de MooBi (Moodle Bilíngue). Para a otimização foram implementados e integrados novas tecnologias, consideradas requisitos para interação bilíngue. Esses requisitos estão descritos na próxima seção.

\section{Requisitos para ambiente bilíngue}

A implementação de um protótipo possibilita realizar verificações e experimentos mais reais, no intuito de avaliar algumas de suas características [SOMMERVILLE, 1995]. Para desenvolver o protótipo foram elencados requisitos funcionais e não funcionais. Os requisitos foram verificados e analisados em relação ao Moodle 2.6.1 e, quando da ausência de algum item, foi verificada a possibilidade de implementação e integração à plataforma. Os requisitos funcionais e não funcionais, bem como a necessidade ou não de implementação e integração, estão detalhados nas próximas seções.

A Prototipação é uma abordagem evolutiva do desenvolvimento de software e envolve:
1. modelo do protótipo;
2. implementação do protótipo;
3. testes e;
4. até um sistema futuro.

Nesse caso todas as etapas de prototipação foram concretizadas, caracterizando o sistema MooBi.

\section{Plataforma integrável}

Esse requisito tem como objetivo selecionar uma plataforma que possibilite a integração de outras tecnologias (internas e externas) no ambiente. Está em conformidade com o framework de Wenger et. al (2005), quando este se refere a integração e caracterização de um ambiente digital para o ensino com foco nas comunidades de prática. Da mesma forma se encontra em consonância com os princípios básicos do documento Web Content Accessibility Guidelines (WCAG), em sua versão 2.0 WCAG2o (2015), principalmente no que se refere à robustez do sistema.

O Moodle, devido à sua característica de desenvolvimento open source e comunitário apresenta periodicamente novas versões do ambiente. No momento da pesquisa, adotou-se a versão Moodle 2.6.1 por ser uma das mais atualizadas, por ter interface com design responsivo ${ }^{3}$ e por estar em consonância com Wenger et. al (2005), ao dar suporte à integração de novas ferramentas e tecnologias.

\section{Interface bilíngue}

Um dos requisitos básicos de qualquer artefato é oferecer uma interface eficaz, eficiente, fácil de aprender e de usar (amigável). A cartilha de acessibilidade da W3CBRASIL (2015) informa que ser acessível na $w e b$ significa perceber, entender, navegar, interagir e contribuir para a web. Todavia as diretrizes da WCAG20 (2015) apresentam poucas informações sobre acessibilidade da interface para língua de sinais. O item 3.1.5 das diretrizes descreve que não existe uma técnica única que auxilie todo tipo de usuário. No caso de usuários surdos, o documento sugere duas possibilidades: criar uma versão em língua de sinais análoga à da língua oral (escrita) ou criar um único ambiente em uma combinação das línguas (bilíngue).

Nessa pesquisa foi optado pela interface bilíngue. Pressupõe-se que um ambiente único é mais adequado à formação de capital social e de outras modalidades que geram capital de conhecimento, tais como, capital humano, cultural, reputacional, aprendizagem e tangível (Wenger et al., 2013).

A página inicial do MooBi permite o acesso ao sistema, por meio de um cadastro (usuário e senha). Cada item do menu se encontra nas duas línguas: textual em português, vídeo em libras e em Sig$n W$ riting (escrita de sinais). A Figura 2 ilustra estas opções, sendo que o acesso aos vídeos e a escrita de sinais se dá por meio de cliques nos ícones mão azul e mão vermelha respectivamente. 


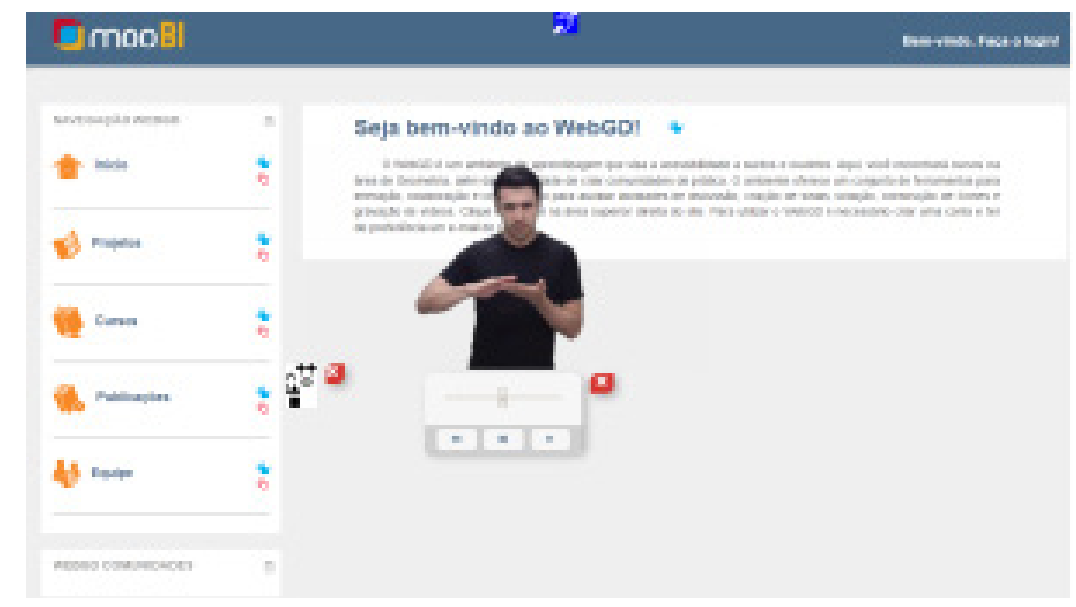

Fig. 2 - Página inicial do MooBi

Na elaboração e edição dos vídeos, foram observadas as recomendações de Debevc et al. (2010) e de Flor et al. (2014), os quais citam o uso de vídeos com fundo transparente e flutuantes. Assim, foi desenvolvido tais funcionalidades para testar com ao público alvo.

Para criar os vídeos flutuantes e transparentes foi utilizado tecnologias como o HTML5 e JavaScript com framework JQuery. Para os vídeos com fundo transparentes a solução foi empregar a tecnologia de canal alfa, a qual possibilita a definição da opacidade (nível de transparência) de um pixel em uma imagem. Foram observadas também sugestões tempo, tamanho e resolução do arquivo e elementos referente ao intérprete [FLOR et al. 2014]. Além das etapas necessárias para criar os vídeos, foi desenvolvido um plug-in para agregar esses vídeos à plataforma Moodle. Os vídeos também fazem parte do ambiente interno.

\section{Comunidades de Prática (CoP)}

Esse trabalho se fundamenta na Teoria das Comunidades de Prática (CoPs) [WENGER, 1989]. Dessa forma, possibilitar a criação de comunidades informais (abertas ou fechadas) por qualquer usuário da plataforma é uma das características consideradas cruciais. Criar suas próprias comunidades faz com que desenvolvam naturalmente suas habilidades em grupos nos quais conhecem e confiam. As comunidades abertas qualquer pessoa cadastrada no ambiente pode fazer parte. No caso de comunidades fechadas, somente com o convite ou aceite do proprietário da CoP.
Neste contexto, foi realizado uma análise da plataforma Moodle 2.6.1, para verificar se a versão atende ao requisito de Comunidades de Prática formais e informais. Em resposta, constatou-se que a versão continuava com as mesmas funcionalidades das anteriores, isto é, uma comunidade só pode ser criada dentro de um curso ou de uma determinada disciplina, mantendo a característica de comunidades formais. A característica de informalidade na criação, um dos requisitos da teoria de CoPs foi concebida por meio de programação (intervenção no código do Moodle), o que demandou a criação de novas tabelas e novos relacionamentos entre elas, no banco de dados do Moodle [SAITO et al., 2014] .

O ambiente de comunidades oferece a opção de visualizar todas as comunidades ou somente aquelas de que o membro participa, ou ainda a opção de cadastrar uma nova (Figura 3). Estando dentro de uma comunidade, Figura 4, seus membros podem adicionar ou deletar arquivos (fotos, textos, vídeos), gravar seu próprio vídeo, postar no fórum, enviar e-mail, enfim, tem a possibilidade de se expressar usando sua própria língua. 


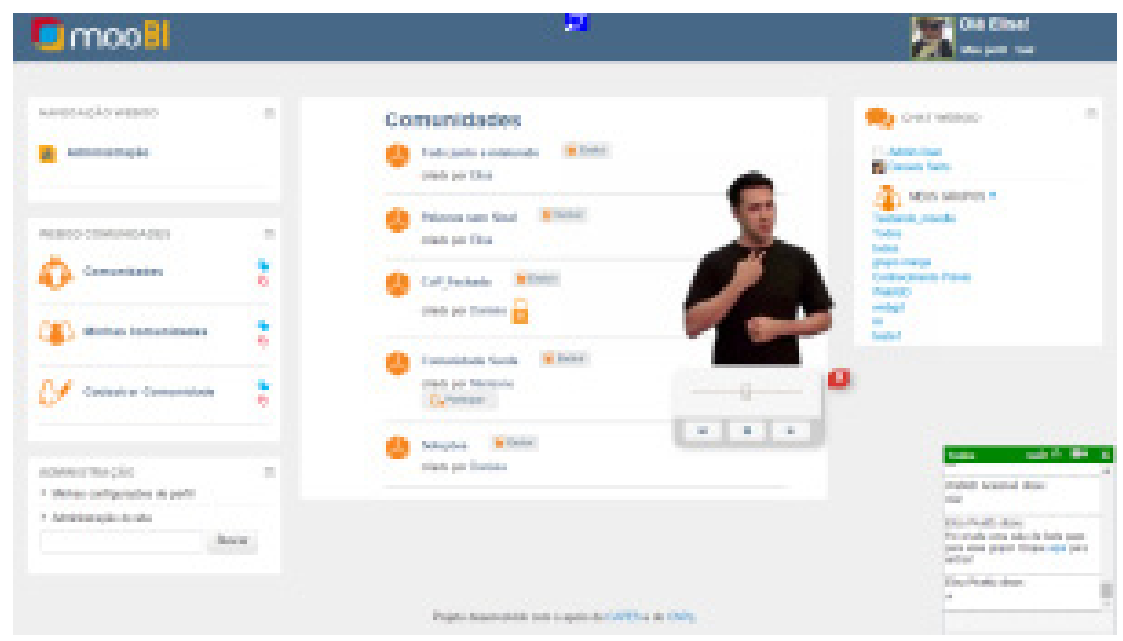

Fig. 3 - Ambiente Comunidades

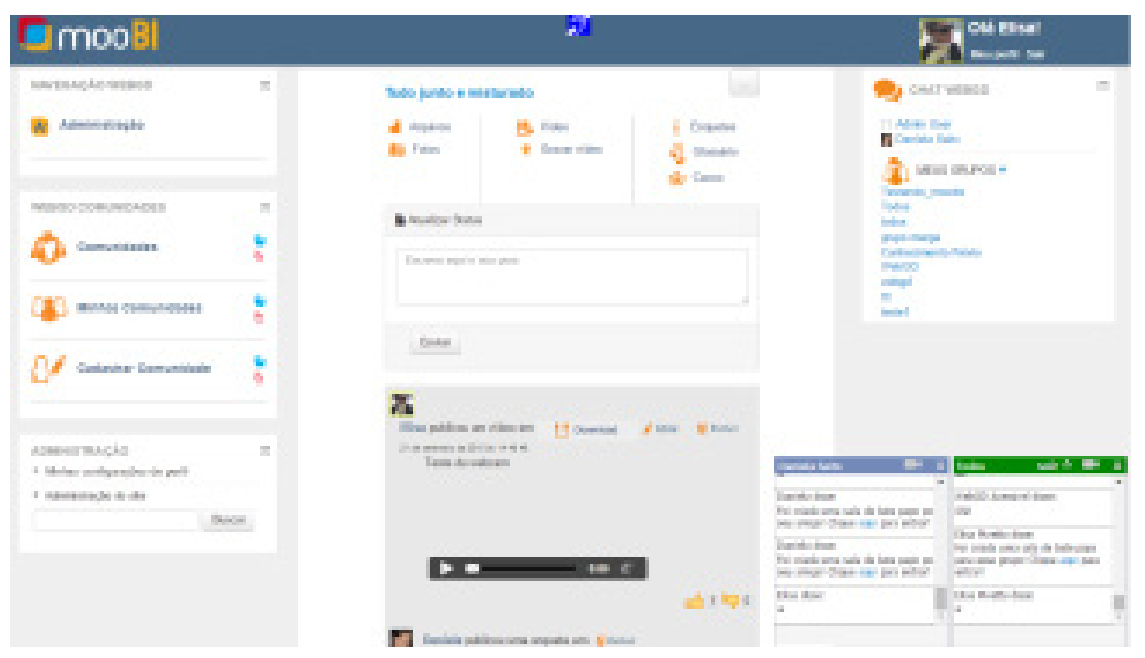

Fig. 5 - Dentro de uma comunidade

\section{Chat privativo e chat em grupo}

A proposta do MooBi é permitir uma interação mútua (entre os participantes da comunidade) e reativa (entre o participante e a máquina), síncrona e assíncrona [PRIMO, 2003]. Assim, foi desenvolvido e disponibilizado em todo o ambiente uma ferramenta de chat, que possibilita interações privativas e em grupo pois na análise do Moodle, constatou-se que a plataforma não possui ferramenta adequada. O sistema tem um chat, mas as conversas são definidas por datas pré-agendadas na plataforma além de não oferecer privacidade de conversas en- tre os participantes. Respeitando os princípios de acessibilidade e os requisitos não funcionais estabelecidos, foram utilizadas as tecnologias: HTML5, CSS3, Javascript e o banco de dados MySql. Via JavaScript, foi desenvolvida uma apresentação dos participantes que estão online, por meio de um menu lateral, que é atualizado automaticamente de acordo com a entrada e saída do ambiente, junto a cujo nome aparece sua foto. A Figura 4 ilustra no canto inferior direito as janelas de chat individual (cor azul) e chat em grupo (cor verde). 


\section{Fórum de discussão interativo}

Na otimização do ambiente, foi desenvolvido um fórum de discussão a fim de tornar o conhecimento tácito em explícito, gerando capital de conhecimento tangível. Isso é possível por meio de postagens, upload e download de arquivos, inserção de vídeos, enquetes, glossário e ferramentas de desenho colaborativas.

Uma opção implementada é o ato de "curtir" e "não curtir" cada evento, porém de maneira anônima, isto é, sem identificar a pessoa que avaliou a postagem. Como é um ambiente de ensino e aprendizagem, pressupõe-se que manter o anonimato é importante para não afetar as relações.

\section{Captura de vídeo}

Um requisito para ambiente bilíngue é possibilitar o registro das opiniões não somente na modalidade português escrito, mas também em Libras (vídeo). Assim, a solução foi desenvolver uma ferramenta para a captura de vídeo, de maneira que o interagente possa gravar o seu próprio vídeo por meio de uma webcam e caso queira, postá-lo na comunidade, sem necessidade de software externo, visando aumentar a portabilidade do sistema (requisito não funcional). Esse recurso pode ser desenvolvido usando a tecnologia Flash ou tecnologia como o HTML5. A opção foi desenvolver em HTML5 pelos seguintes motivos:

a. redução no uso de aplicações em Flash devido às deficiências no que se refere ao suporte ao desenvolvimento de sites acessíveis e por ser proprietária;

b. previsão de que o HTML5 passe a ser adotada como padrão.

Para gravar seu próprio vídeo, o interagente deve ter apenas uma câmera instalada no computador. Quando gravado, basta salvar fazendo download. Posteriormente poderá postar o vídeo no fórum das comunidades. Ver Figura 5.

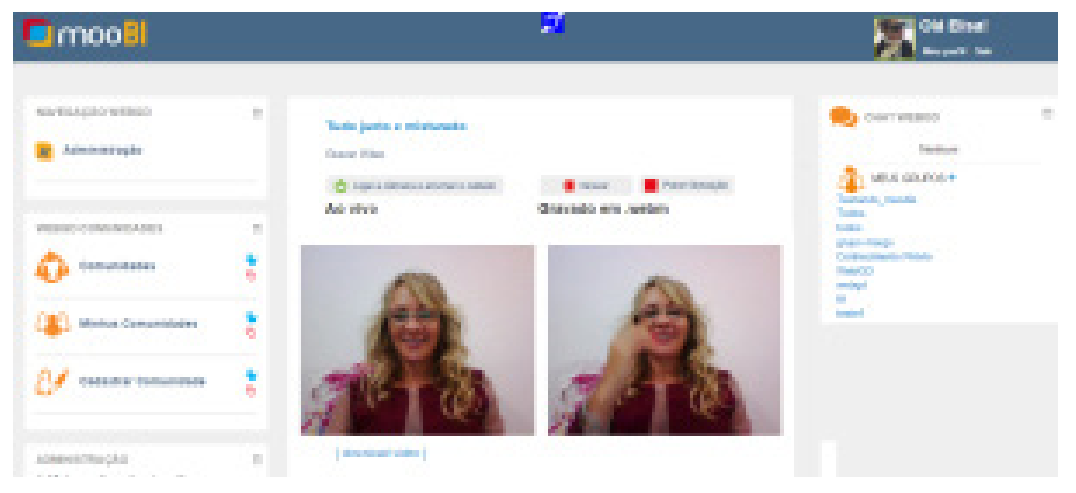

Fig. 4 - Ferramenta em HTML5 para captura de vídeo

O formato selecionado para a gravação foi o WebM, um formato aberto, livre de royalty. Informações adicionais estão em Saito, Pivetta e Almeida (2015).

\section{Videoconferência}

A disponibilização de videoconferência é um requisito importante para comunicação, em especial a dos surdos. Atendendo a Trindade (2013) e à proposta de código fonte aberto, foi selecionado o software Mconf (http://mconf.org/), também é utilizado pela RNP (Rede Nacional de Ensino e Pesquisa). Para integrar o Mconf ao Moodle foram realizadas algumas customizações, possibilitando aos participantes a utilização sem necessidade de pré-agendamento. $\mathrm{O}$ acesso à videoconferência é realizado por meio do ícone "filmadora", que se encontra na barra do chat (privativo ou em grupo). Esse acesso pode ser feito a qualquer momento. A comunicação exige que ao menos duas pessoas estejam no ambiente. Não é necessário um login, pois o software está integrado ao Moodle. A Figura 6 ilustra o ambiente e algumas ferramentas. 


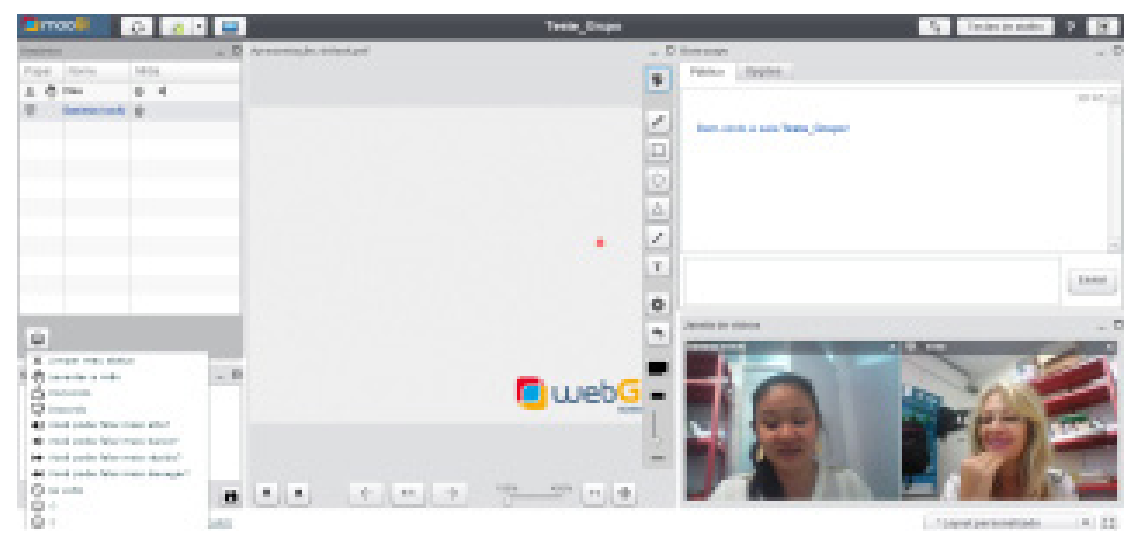

Fig. 6 - Videoconferência com o Mconf

\subsection{Correio-eletrônico}

O Moodle, por padrão, não tem a opção de cadastramento de $e$-mail ativada. Para ativar é necessário que o administrador do sistema gerencie essa autenticação, além de que o e-mail nativo do Moodle funciona somente para os cursos e disciplinas. No MooBi a opção de enviar e-mail foi otimizada para que todos que acessam o ambiente possam fazer uso. Na otimização foi optado por direcionar os e-mails ao cliente/servidor do Gmail. Todavia há outros servidores que podem ser utilizados ou até mesmo um da instituição onde se encontra instalada a plataforma. O processo "busca" no banco de dados das comunidades os e-mails dos participantes e coloca-os em uma lista. Posteriormente, é gerado um link de comunicação com a API (Application Programming Interface) do Gmail, disponibilizada pela Google, inserindo como destinatá- rios a lista de e-mails. Após a execução do link, o interagente é direcionado automaticamente para a página do Gmail e, consequentemente, poderá enviar $e$-mails.

\subsection{Tradutor automatizado}

Levando-se em conta que vídeo em Libras é um requisito e que ter vídeos disponíveis para todos os conteúdos dinâmicos pode ser custoso e complexo, uma opção foi integrar um software tradutores. Por meio de uma parceria com a empresa Prodeaf foi integrado o WebLibras no Moodle (Figura 7), a fim de verificar a importância, necessidade e benefício dos tradutores automatizados para a interação. A tradução do WebLibras atualmente é somente de

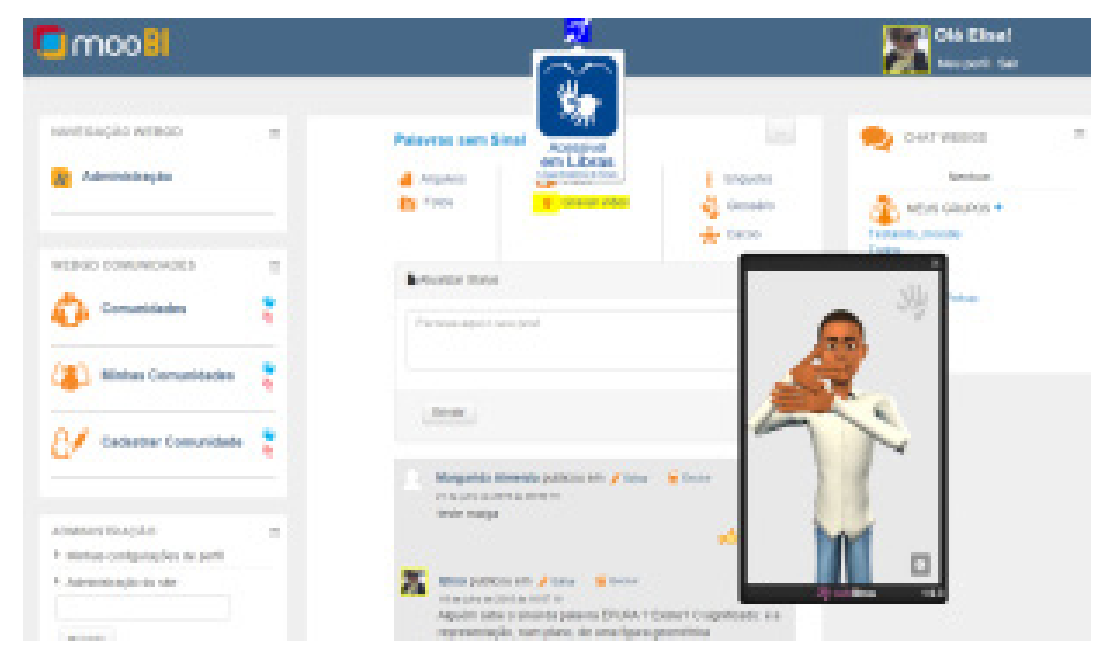

Fig. 7 - Tradutor automatizado 
Português para Libras.

Para testar se os requisitos contribuem para um ambiente bilíngue, fornecendo interação com suporte a Comunidades de Prática, foi realizado uma pesquisa. Os procedimentos, a verificação e os resultados estão descritos na próxima seção.

\section{Verificação de requisitos}

Um requisito funcional deve ser passível de testes por meio do protótipo e de alguma técnica de verificação, de modo a verificar se o sistema cumpre tal requisito e se algum precisa ser remodelado. Para verificação dos requisitos, foi realizada uma investigação com o público alvo. A técnica utilizada foi de ensaios de interação, e, como complemento, foi aplicado um questionário, a fim de avaliar a satisfação ou insatisfação em relação ao protótipo e à sua operação. Os participantes foram instruídos a interagir no ambiente e, sempre que possível, a externar as dúvidas e a fazer comentários. O público alvo foi composto por trinta e três pessoas, sendo este grupo composto por professores e alunos (dezesseis surdos e dezessete ouvintes) de cursos técnicos, tecnológicos e do ensino superior, todos conhecedores do Moodle. Os participantes ouvintes são pessoas que estão envolvidas, de alguma forma, com a educação dos surdos ou acessibilidade na web.

Os ensaios foram executados em pequenos grupos e também individualmente. Quando se tratava de surdos, a sinalização foi intermediada por intérpretes conhecedores de Libras. Os eventos foram filmados (vídeo) e gravados (áudio) e posteriormente transcritos para viabilizar a análise.

Na pesquisa realizada, a modalidade ambiente digital bilíngue foi considerada por todos como a ideal para interação. Quanto ao requisito comunidades de prática, foi implementado dentro do MooBi atendendo a teoria de Wenger (1989).

É indiscutível a importância para pessoas surdas ter no ambiente digital ferramentas para comunicação em vídeo. Esse requisito foi dado por todos como essencial. É uma ferramenta para o desenvolvimento do capital social, humano, reputacional, cultural e de aprendizagem.

Quanto aos vídeos, diferenciando do resultado da pesquisa de Debevc et al. (2010), a qual mostrou grande aceitação por vídeos transparentes e flutuantes, observou-se nessa pesquisa certa rejeição. Entre os surdos que opinaram, $71 \%$ consideram que a transparência atrapalha a compreensão, pois tende a confundir com o fundo da página. Assim, $48 \%$ dos surdos manifestaram preferência por ví- deo flutuante sem transparência, 29\% por flutuante com transparência e 23\% não flutuante (janela fixa) e sem transparência. Um participante ouvinte e conhecedor da língua de sinais comenta: "o vídeo flutuante é um ganho extremo, mas a transparência, quando visualizado muitos vídeos com conteúdo de fundo, pode causar cansaço visual”.

Em relação aos ouvintes (93\%) consideraram a opção flutuante e transparente a mais indicada. Pressupõe-se que, como os ouvintes não buscam perceber o significado da língua por meio do vídeo, as respostas positivas em relação à transparência foram mais pela tecnologia empregada do que pela compreensão da sinalização.

Uma das ferramentas que foi considerada por muitos como uma inovação no MooBi e importante para interação foi a de captura de vídeo com a webcam. Segundo os respondentes da pesquisa, a ferramenta integrada no ambiente motiva, facilita e agiliza o processo de comunicação. Algumas opiniões de surdos:

S1: Essa ferramenta que vocês criaram a gente pode na mesma hora estar enviando a atividade [..] já grava e já manda pelo Moodle mesmo, isso tá revolucionando, vamos dizer, tá mudando muito... tá facilitando muito.

S3: É ótimo essa ferramenta [..] por exemplo, eu tenho a câmera, a câmera que eu faço a gravação e tenho o vídeo pronto já, então isso tá excelente.

S4: Mudou mesmo, sentia falta de uma gravação direto dentro do ambiente.

\section{S5: Essa utilização tá excelente. Me apaixonei.}

Gravar e disponibilizar seu próprio vídeo proporciona ao surdo uma participação autônoma, pois utiliza sua língua para se comunicar. A ferramenta de captura fornece meios para a criação e inserção de vídeo que podem ser compartilhados facilmente na linha do tempo do fórum. O interagente não precisa se preocupar com softwares de gravação e nem formatos de vídeo, o que agiliza todo o processo.

O e-mail, mesmo não sendo muito aceito pelos surdos por ser muito textual, é um meio de comunicação assíncrona bastante usado. É uma ferramenta fonte de capital social e tangível, pois muitas interações mútuas e troca de informações acontecem por intermédio dele.

No que diz respeito ao tradutor automatizado, a maioria dos surdos mostraram-se indiferentes e não consideram muito útil. Comentam que esses softwares precisam ser aperfeiçoados, tanto na formação das frases, quanto nos sinais e principalmente nas expressões. Porém acreditam que podem ser fonte de auxílio para verificar um deter- 
minado sinal em Libras. Alguns comentaram que o tradutor automático é mais indicado para os ouvintes, como a própria pesquisa indicou. Mesmo com certa rejeição, todos consideram que é interessante deixá-lo no ambiente.

Na interação, o fórum de discussão é um espaço crucial, com funções de promover o diálogo e o compartilhamento de informações. É um arcabouço de evidências explícitas das manifestações do capital do conhecimento. Nele é possível verificar o engajamento, a motivação, a postura, a satisfação, o compromisso, o interesse, as contribuições, as abordagens inovadoras, os relacionamentos, entre outros elementos importantes para a prática e cultivo de uma comunidade. Esse capital em Comunidades de Prática se constrói na linguagem, no modo de se comunicar, nas interações mutuas e reativas.

O participante de uma comunidade não é apenas uma pessoa "navegando", mas é alguém que interage, constrói relacionamentos, opinião e compartilha seus conhecimentos. O ato de "curtir", grosso modo, remete a interagir com uma determinada postagem, de modo positivo. Mas, um clique "positivo" ou "negativo" pode mudar a maneira de um membro ou uma comunidade proceder. Através de um simples clique em um botão, os membros saberão que determinado conteúdo marcado foi aprovado ou reprovado. As atitudes, as motivações, a confiança, o compromisso, a conduta (capitais sociais, humanos e reputacionais) podem se alterar, fortalecendo ou enfraquecendo as relações.

Algumas situações geraram polêmicas, como a existência do ícone "não curti". Todavia em um ambiente de ensino e aprendizagem, talvez seja interessante mostrar ao autor da postagem, que tal atividade não foi bem realizada. Por outro lado, o estrago que a rejeição pode causar na autoestima mais vulnerável pode ser grande. Nessas horas, convém pender para o viés mais tranquilo e prático: se curtiu, apoia; se não curtiu, poupa-se, o que seria o menos perturbador. No MooBi, utilizou-se o "curtir" e o "não curtir" sem identificar quem o fez. Porém, observou-se nos relatos dos ensaios que isso não impede a pessoa que fez a postagem, ao receber alguns "não curtir", de ficar abalada.

Complementado, bem justificada a opinião de uma professora quando comenta que, se a postagem consta de vídeo expondo a imagem da pessoa, o avaliador não deve ficar no anonimato. Por outro lado, se só existe o "curtir" e se algo não ganha muitas curtidas, parece que desagradou, mas não se sabe ao certo. Enfim, a liberdade de expressão, visto que o ambiente é educacional, deve ser exercida com responsabilidade.

O alinhamento nas CoPs requer que os indivíduos envolvidos tenham noção de suas responsabilidades e, ao se envolverem, entrem em sintonia, para o alcance dos objetivos em comum. Fica como sugestão uma análise mais apurada para saber qual é a melhor forma de avaliar uma postagem em Comunidades de Prática.

\section{Considerações Finais}

Diferentes culturas trazem diferenças linguísticas, de costumes, e de percepção do mundo atrelado às suas experiências. O uso da língua mostra-se grande responsável pela integração e pelo convívio social. Assim, durante todo o processo desta investigação constatou-se que ambas as línguas devem permear os ambientes virtuais, da mesma forma e intensidade. Idealizar um ambiente com CoPs atuantes, onde o diferencial está em possibilitar as interações atendendo a uma cultura bilíngue, é desafiador, porém benéfico.

Assentado nas dimensões da prática, do compartilhamento e dos critérios básicos de uma comunidade, tais como envolvimento, criatividade e alinhamento, o ambiente proposto pode servir de suporte para verificar se as dimensões são contempladas em uma Comunidade de Prática bilíngue. Fica como sugestão verificar se o capital social em ambiente bilíngue influencia na sustentabilidade da comunidade.

Mesmo não sendo a tecnologia que mantém uma CoP viva, ela tem grande importância nas relações e no compartilhamento de informações. Com nível de inovação, foram desenvolvidos: vídeos flutuantes com fundo transparente, software de captura de vídeo em HTML5, tecnologia para conversas instantâneas (chat) desenvolvido em Ajax e avaliação e enquetes dinâmicas, dentro de um ambiente estático, o Moodle.

O MooBi está disponível no endereço http://webgd.egc.ufsc.br para utilização e futuras pesquisas. As tecnologias desenvolvidas e integradas no protótipo estão no repositório GitHub no endereço https://github.com/ MoobiEgc em código fonte aberto. Espera-se que a comunidade possa reutilizar esses módulos para novas investigações e verificações, com melhorias e otimizações, sempre com foco na inclusão e acessibilidade na web. 


\section{Referências}

Bauman, H.L. \& Murray, J.M. Deaf-gain and the Future of Human Diversity (Deaf Studies in the 21st Century. 2010.

BRASIL. Lei no ${ }^{0}$ 10.436, de 24 de abril de 2002. Dispõe sobre a Língua Brasileira de Sinais, 2002.

BRASIL. Decreto nํㅜ 5.296 de 2 de dezembro de 2004. http://www.planalto.gov.br/ccivil_03/_ ato2004-2006/2004/decreto/d5296.htm

BRASIL. Lei n ${ }^{0}$ 13.146, de 6 de julho de 2015. Lei Brasileira de Inclusão da Pessoa com Deficiência (Estatuto da Pessoa com Deficiência), 2015.

COCHRANE. Curso de Revisão Sistemática e Metanálise. Disponível em: http://www. virtual.epm.br/cursos/metanalise/. Acesso em Maio de 2012.

Debevc et al., Improving multimodal web accessibility for deaf people: sign language interpreter module (Springer Science Business Media, LLC), 2010.

Fajardo, I., Vigo, M., \& Salmerón, L. Technology for supporting web information search and learning in Sign Language (Interacting with Computers, v. 21, n. 4, pp. 243-256), 2009.

Flor, C., Bleicher, S. \& Vanzin, T. Recomendações ao desenvolvimento de interfaces para ambientes virtuais voltados a surdos (Ulbricht, V. R.; Vanzin, T. \& Quevedo, S. R. P. (Org.). São Paulo: Pimenta Cultural, 2014, pp. 186-214).

Gabardo, S. R. P., Quevedo, S. \& Ulbricht, Vania. Estudo comparativo das plataformas de ensinoaprendizagem. Encontros Bibli: Revista eletrônica de Biblioteconomia e Ciência da Informação, Florianópolis, n. esp., 2. Sem., 2010.

IBGE. Instituto Brasileiro de Geografia e Estatística (Disponível em: http://www.ibge.gov. br/censo2010/. Acesso em abril de 2012).

Lave, J. \& Wenger, L. Situated Learning (Cambridge University Press), 1998.

Hutchins, E. Distributed Cognition (San Diego. IESBS University of California, 2000).

MOODLE. Ambiente Moodle (Disponível em: http://www.moodle. org.br/. Acesso em julho de 2015).

Pivetta, E.M., Saito, D. \& Ulbricht, V. Conceitos e Práticas em Ambiente virtual de aprendizagem Inclusivo (Org. Vania Ribas Ulbricht, Tarcisio Vanzin, Silvia R. Quevedo, e-book. 2013. pp. 215-242), 2013.

Primo, A.F.T. Interação Mediada por Computador: a comunicação e a educação a distância segundo uma perspectiva sistêmico-relacional (Tese apresentada como parte dos requerimentos 
para obtenção do Título de Doutor pelo Programa de Pós- Graduação em Informática na Educação da Universidade Federal do Rio Grande do Sul), 2013.

Quivy R. \& Campenhoudt, L. V. Manual de Investigação em Ciências Sociais (Gradiva. Lisboa, 4 ed.), 2005.

Saito, D. S. \& Ulbricht, V.R. Learning Managent Systems and Face-to-Face Teaching in Bilingual Modality (Libras/Portuguese) Revista IEEE América Latina, v. 10, 2012, pp. 2168-2174

SAITO, D.S., PIVETTA, E.P. \& ALMEIDA, A.M.P. Ferramentas para Comunicação e Compartilhamento de Informações em Comunidades de Prática (E-Book. Hipermídia e Interdisciplinaridade na Geração de Conhecimento. CONAPHA. 2015. Disponível em http:// conahpa.sites.ufsc.br/exposicaolayout/. Acesso julho de 2015).

Schneider, E.I. Uma contribuição aos ambientes virtuais de Aprendizagem (AVA) suportados pela teoria da Cognição situada (TCS) para pessoas com Deficiência auditiva (Dissertação de mestrado, EGC/UFSC), 2012.

Sommerville, I., Engenharia de Software (São Paulo: Pearson Addison Wesley, 6ª ed.), 1995.

Trindade, D.F.G. InCoP: um framework conceitual para o design de ambientes colaborativos inclusivos para surdos e não surdos de cultivo de comunidades de prática (Tese de Doutorado em Informática, Curitiba: Programa de Pós-Graduação em Informática do Setor de Ciências Exatas da Universidade Federal do Paraná), 2013.

Rézeau, J.,Le cas de l'apprentissage de l'anglais en Histoire de l'art à l'université (Université Victor Segalen Bordeaux 2. UB. Tese de doutorado. 2001. Disponível em: http://joseph. rezeau.pagesperso-orange.fr/. Acesso em agosto de 2012).

Wenger, E., White, N., Smith, J. D. \& Rowe, K. Technology for Communities, 2005. (Disponível em: http://pt.scribd.com/doc/2531741/ Technology-for-communities-WengerCEFRIO-Book- Chapter-v-5-2. Acesso em novembro de 2014).

WENGER, E. et al. Comunities of practice: a brief introduction (Disponível em http://wengertrayner.com/wp-content/uploads/2013/10/o6-Brief-introduction-to-communities-of-practice.pdf. Acesso em setembro de 2014).

WCAG20. How to Meet WCAG 2.o: A customizable quick reference to Web Content Accessibility Guidelines 2.o requirements (success criteria) and techniques (Disponível em http://www.w3.org/ WAI/WCAG2o/quickref/\#navigation-mechanisms. Acesso em Janeiro 2015).

W3C. World Wide Web Consortium (Disponível em http://www.w3.org. Acesso em maio de 2014).

W3CBrasil, Cartilha acessibilidade na web (Disponível em: http://www.w3c.br/pub/ Materiais/PublicacoesW3C/cartilha-w3cbr-acessibilidade-web-fasciculo-I.html. Acesso em fevereiro 2015). 


\section{Agradecimentos}

Ao PPGEGC da UFSC, à Universidade de Aveiro - Portugal, a Capes, ao CNPq e, em especial, a Universidade Federal de Santa Maria (UFSM) e ao Instituto Federal de Santa Catarina (IFSC). 